\title{
ANIMAL MODELS FOR IMPLANT BIOMATERIAL RESEARCH IN BONE: A REVIEW
}

\author{
AI Pearce*, RG Richards, S Milz, E Schneider and SG Pearce \\ AO Research Institute, AO Foundation, Clavadelerstrasse 8, Davos, Switzerland
}

\begin{abstract}
Development of an optimal interface between bone and orthopaedic or dental implants has taken place for many years. In order to determine whether a newly developed implant material conforms to the requirements of biocompatibility, mechanical stability and safety, it must undergo rigorous testing both in vitro and in vivo. Results from in vitro studies can be difficult to extrapolate to the in vivo situation. For this reason the use of animal models is often an essential step in the testing of orthopaedic and dental implants prior to clinical use in humans. This review discusses some of the more commonly available and frequently used animal models such as the dog, sheep, goat, pig and rabbit models for the evaluation of bone-implant interactions. Factors for consideration when choosing an animal model and implant design are discussed. Various bone specific features are discussed including the usage of the species, bone macrostructure and microstructure and bone composition and remodelling, with emphasis being placed on the similarity between the animal model and the human clinical situation. While the rabbit was the most commonly used of the species discussed in this review, it is clear that this species shows the least similarities to human bone. There were only minor differences in bone composition between the various species and humans. The pig demonstrates a good likeness with human bone, however difficulties may be encountered in relation to their size and ease of handling. In this respect the dog and sheep/ goat show more promise as animal models for the testing of bone implant materials. While no species fulfils all of the requirements of an ideal model, an understanding of the differences in bone architecture and remodelling will assist in the selection of a suitable model for a defined research question.
\end{abstract}

Key Words: Animal-models, biomaterials, osseointegration, bone, implant, dog, pig, sheep, goat, rabbit.

Address for correspondence*

A.I. Pearce

AO Research Institute, AO Foundation

Clavadelerstrasse 8, CH-7270 Davos Platz

Switzerland

Telephone Number: $+41(0) 814142311$

E-mail: alexandra.pearce $@$ aofoundation.org

\section{Introduction}

The development and modification of orthopaedic and dental implants has taken place for many years in an effort to create an optimal interaction between the body and the implanted material. The goal of achieving an optimal bone-implant interface has been approached by the alteration of implant surface topography, chemistry, energy and charge as well as bulk material composition. Schmidt et al. (2001) defines an ideal bone implant material as having a biocompatible chemical composition to avoid adverse tissue reaction, excellent corrosion resistance in the physiologic milieu, acceptable strength, a high resistance to wear and a modulus of elasticity similar to that of bone to minimise bone resorption around the implant. The features relating to implant safety such as avoidance of adverse tissue reaction and resistance to wear and corrosion are of high clinical significance for implants used in long-term clinical situations in both human and veterinary medicine as there have been some links between prolonged exposure to non-biocompatible materials and neoplastic tissue responses. In order to determine whether a new material conforms to the requirements of biocompatibility and mechanical stability prior to clinical use, it must undergo rigorous testing under both initial in vitro and then in vivo conditions.

In vitro testing is popular for the characterisation of bone-contacting materials, particularly as medical researchers embrace the principles of animal reduction. It is accepted that in vitro testing be used primarily as a first stage test for acute toxicity and cytocompatibility to avoid the unnecessary use of animals in the testing of cytologically inappropriate materials. The term biocompatibility is often incorrectly used with in vitro tests, as biocompatibility can only be used in the case of animals or humans (in vivo), with the correct term being cytocompatibility for in vitro tests (Richards et al., 2001).

In vitro cell culture is centred upon the growth of cells no longer organised into tissues, where cells are collected either through enzyme digestion or mechanically from native tissue and proliferate in a suspension or attached to a substrate surface as a monolayer. In vitro testing gives information regarding cytotoxicity, genotoxicity, cell proliferation and differentiation (Hanks et al., 1996; Nahid and Bottenberg, 2003) and is more easily standardised and quantifiable than in vivo testing (Nahid and Bottenberg, 2003). In vitro studies are also useful for screening new materials for product quality and the release of potentially harmful additives incorporated during the manufacturing process (Pizzoferrato et al., 1994). However, in vitro characterisation is not able to demonstrate the tissue response to materials, instead being 
confined to the response of individual cell lines or primary cells taken from animals. In addition, cellular responses, such as cytotoxicity due to the presence of metal ions, can vary between cell lines and passage number (Wataha et al., 1994). In vitro tests may also overestimate the level of material toxicity and are limited to acute studies of the effects of toxicity due to the relatively short lifespan of cultured cells (Pizzoferrato et al., 1994).

In vitro tissue culture maintains small tissue fragments of tissue, but does not necessarily preserve architecture. In vitro organ culture maintains tissue or organs (in part or whole), which may allow some differentiation and preservation of architecture and function (though systemic factors are absent, the lack of vascularisation limits nutrient and oxygen supply and waste removal and therefore extrapolation of results to the in vivo situation limits the model). In vitro cells may suffer from phenotypic drift, which may be due to dissociation of cells from their three dimensional geometry and/or growth on a two dimensional surface. The dynamic properties of cell culture are difficult to control in vitro and it is difficult to recreate the appropriate cell interactions found in vivo. One major limitation to bone culture is the lack of controlled physiological loading since without load bone will increase resorption, as is seen in patients after prolonged bed rest (Vico et al., 1987). No in vitro cell culture system is able to produce loading that simulates the in vivo situation and currently very few ex vivo systems are able to approach such physiological loading (and usually only with small tissue samples) (Davies et al., 2006). For these reasons animal models are essential for evaluating biocompatibility, tissue response and mechanical function of an orthopaedic or dental material prior to clinical use in the human.

Animal models allow the evaluation of materials in loaded or unloaded situations over potentially long time durations and in different tissue qualities (e.g. normal healthy or osteopenic bone) and ages. Not only can the tissues in the immediate vicinity of the implant be assessed, tissues in remote locations can be studied, which is particularly relevant to the study of wear particle debris. In human patients, such debris has been reported to travel into different distant organs such as liver and spleen (Urban et al., 2000). While animal models may closely represent the mechanical and physiological human clinical situation, it must be remembered that it is only an approximation, with each animal model having unique advantages and disadvantages. Currently there are numerous models for testing implant materials in vivo, ranging in purpose from the assessment of protein adsorption and soft tissue adherence to the integration of bone and the dissemination of implant wear particles. This review examined the literature relating to animal models used in the evaluation of bone-implant interactions.

\section{Implant Design}

For testing orthopaedic and dental implants, it is necessary to use a model which is reproducible and in which implant dimensions are comparable to those used in humans. The number and size of implants to be tested will influence directly the species of animal chosen for a study. The most common implant designs used in animal models are either screw type (threaded) or cylindrical (rod shaped) and less commonly coin, disc, plate or irregular shaped. Regardless of the design, implants should have an appropriate size for the species chosen and for the bone implantation site. Screw type implants have the advantage of producing good initial stability, whereas cylindrical implants are dependent on exact fit in order to be stable within the bone and give accurate results regarding their effect on bone integration (Carlsson et al., 1988). However, analysis of rod or cylindrical shaped implants may be less complicated due to their more simple geometry.

Guidelines are provided for the dimensions of implants for in vivo studies, based on the size of animal and bone chosen and on the implant design, in order to avoid pathological fracture of the test site. Cylindrical implants placed into rabbit tibial and femoral diaphyseal bone should be no larger than $2 \mathrm{~mm}$ in diameter and $6 \mathrm{~mm}$ in length. For larger animals such as sheep, goats and dogs the ISO recommended dimensions of cylindrical implants are $4 \mathrm{~mm}$ in diameter and $12 \mathrm{~mm}$ in length for implantation into the femur and tibia. Orthopaedic bone screw-type implants may range from $2-4.5 \mathrm{~mm}$ depending on the species chosen, with the $4.5 \mathrm{~mm}$ screws generally being reserved for the larger species such as the dog, sheep and pig. The breed of animal used in a study must be considered when choosing the exact implant dimensions as for example, large breeds of sheep may allow the use of implant materials up to $5 \mathrm{~mm}$ in diameter in certain locations such as the tibia and metatarsus (Huffer et al., 2006). It is extremely important that control implants are included in the study design. These implants should be of a material already in clinical use (International Standard ISO 10993-6, 1994) and should allow the outcome data to be related to existing products. The chosen implant design will determine the experimental techniques used to evaluate the material, in particular the mechanical testing techniques. Common mechanical testing used on tissues harvested from in vivo studies include torque removal tests (screw-type implants), pullout tests and push-out tests (screw, cylindrical implants). These tests are used to evaluate the strength of the interaction between the bone and implant surface. High forces encountered during these tests indicate a good integration between the bone and implant surface or in the case of porous materials, a high degree of bone in-growth into the pores of the implant.

Many studies aim to evaluate the effect of implant surface modification on alteration of the bone-implant interaction. In order to draw accurate conclusions regarding the effects of implant modification, one must first accurately determine the implant surface characteristics with regard to the chemical composition of the material and the surface topography. This should be performed both visually (e.g. light microscopy, scanning electron microscopy) and numerically (e.g. profilometry, contact angle, X-ray photoelectron spectroscopy, energy dispersive $\mathrm{X}$-ray microscopy) thus including both qualitative and quantitative data. There are numerous studies that draw conclusions regarding the effect of surface topography on bone formation without having properly characterised the surfaces used, which unfortunately give varying results 
leading to confusion (e.g. describing a surface as rough or smooth, without having measured this numerically).

\section{Animal Selection}

Kirkpatrick et al. (2002) outlines three types of studies which yield data on factors influencing the biological response to materials implanted in bone. These are studies on explanted biomaterials, in vitro techniques and animal models. Desirable attributes of an animal model include demonstration of similarities with humans, both in terms of physiological and pathological considerations as well as being able to observe numerous subjects over a relatively short time frame (Egermann et al., 2005; Liebschner, 2004; Schimandle and Boden, 1994).

When deciding on the species of animal for a particular model there are several factors that should be considered. One must define clearly the research question being addressed prior to selecting the species of animal to be used in the study. According to Schimandle and Boden (1994), animal selection factors include: cost to aquire and care for animals, availability, acceptability to society, tolerance to captivity and ease of housing. A detailed discussion on handling and care of the individual species, listed in this review, will not be made. The welfare and housing of animals is usually covered by a Federal Animal Protection Act and may vary slightly between countries. The Animal Protection acts outline the minimum requirements in terms of housing dimensions, lighting, flooring etc. and must be complied with when undertaking an animal study. Specific features will vary according to species. Other factors include low maintenance care, ease of handling, resistance to infection and disease, interanimal uniformity, biological characteristics analogous to humans, tolerance to surgery, adequate facilities and support staff and an existing database of biological information for the species. In addition to this, the lifespan of the species chosen should be suitable for the duration of the study. More specifically, for studies investigating bone-implant interactions, an understanding of the species specific bone characteristics - such as bone microstructure and composition, as well as bone modelling and remodelling properties, are important when later extrapolating the results to the human situation. Finally the size of the animal must be considered to ensure that it is appropriate for the number and size of implants chosen (Schimandle and Boden, 1994); (International Standard ISO 10993-6, 1994). Hazzard et al. (1992) comment that within a field of study, no single animal model will be appropriate for all purposes, nor can a model be dismissed as inappropriate for all purposes. Furthermore, multiple model systems are likely required to establish a broad body of knowledge (Hazzard et al., 1992).

International standards established regarding the species suitable for testing implantation of materials in bone, state that dogs, sheep, goats, pigs or rabbits are suitable. At least four rabbits and at least two of each of the other species mentioned above should be used for each treatment at each implantation period, though appropriate power calculations should be performed. Long term implantation periods for these species are given as 12,26 ,
52 and 78 weeks and in certain instances (with the exception of rabbits) 104 weeks (International Standard ISO 10993-6, 1994). Although the rat is one of the most commonly used species in medical research, it will not be discussed here due to significant dissimilarities between rat and human bone and the limitations of size making rats unsuitable for testing multiple implants simultaneously.

\section{Canine}

\section{Usage}

The dog is one of the more frequently used large animal species for musculoskeletal and dental research. Unlike other animal species, there is a considerable amount of literature comparing canine and human bone with regard to the usefulness of the $\operatorname{dog}$ as a model for human orthopaedic conditions. A review by Neyt et al. (1998) finds that $\operatorname{dog} s$ and cats were used in $11 \%$ of musculoskeletal research between 1991 and 1995. This is confirmed by Martini et al.(2001) who reports that between 1970 and 2001, 9\% of orthopaedic studies utilised dogs as an animal model. The highly tractable nature of dogs can be beneficial during the post operative healing phase where they may be trained to take an active part in recuperative protocols. However, there are increasing ethical issues relating to the use of dogs in medical research due to their status as companion animals.

\section{Macrostructure}

Depending on the size and breed of dog, there may be some discrepancy in the size and shape of canine bones in comparison to human bones; however, commercially available implants and surgical equipment is available for canine surgery. There are also obvious differences in bone loading with the quadrupedal gait of the dog.

\section{Microstructure}

Wang et al. (1998) investigate the differences in fracture properties between bovine, baboon, rabbit and canine bone and the correlation of compositional and microstructural properties with these differences. While adult human bone has a secondary osteonal structure (osteons greater than $100 \mu \mathrm{m}$ containing blood vessels and with cement lines forming a boundary between adjacent lamellae), canine bone is found to have a mixed microstructure comprising predominantly secondary osteonal bone in the centre of cortical bone, but with, what is called plexiform bone in the areas adjacent to the periosteum and endosteum (Wang et al., 1998). Plexiform or laminar bone as it is also called (Jee et al., 1970) is found predominantly in large, rapidly growing animals and occasionally in children during periods of rapid growth. It is formed more rapidly than secondary osteonal tissue, but provides greater mechanical support than woven bone. It has a brick-like appearance and vascular plexuses within the lamellar bone tissue. It is also concluded from this study that, despite similarities in organic composition, canine bone had significantly higher mineral density than human bone (Wang et al., 1998).

Earlier findings by Kuhn et al. (1989), indicate that while trabecular bone from the distal femur of humans 
and dogs is qualitatively similar in terms of mechanical and mass properties, differences in the coefficients relating to ultimate strain resistance, indicate that canine trabecular bone is able to withstand higher compressive strains before failure than human bone (Kuhn et al., 1989).

\section{Bone composition}

A study by Aerssens et al. (1998) examines the differences in bone composition, density and quality between various species (human, dog, sheep, pig, cow and chicken). It is found that there is most similarity in bone composition (ash weight, hydroxyproline, extractable proteins and IGF1 content) between the dog and human. In terms of bone density the dog and pig most closely represent the human situation. The authors conclude that of the components tested, the characteristics of human bone are best approximated by the properties of canine bone (Aerssens et al., 1998). These results are also supported by earlier findings of Gong et al. (1964), where human and dog cortical and cancellous bone are found to be similar in terms of water fraction, organic fraction, volatile inorganic fraction and ash fraction.

\section{Bone remodelling}

Another difference between human and canine bone which may be of importance when assessing the effect of implant modifications, is the difference in the rate of bone remodelling between the species. This is an important consideration as implant associated changes evident in a canine model may not be as apparent in the human situation where there is a lower rate of remodelling (Bloebaum et al., 1991; Bloebaum et al., 1993). While there are structural similarities in trabecular bone turnover between dogs and humans (Kimmel and Jee, 1982), it is difficult to make an exact comparison of bone turnover between these species from data presented in the literature. Trabecular bone turnover rates in dogs is found to be highly variable between bone sites. For example, the lumbar vertebral body has a bone turnover rate of close to $200 \%$ per year in young adult male beagles. In the talus the turnover is $12 \%$ per year. The average whole body trabecular bone turn over is calculated as approximately 100\% (Kimmel and Jee, 1982). Not only is trabecular bone turnover variable between bone sites within the one individual, there is also large variation in trabecular bone turnover between individuals, for example the mean turnover rate of bone taken by transilial biopsy from young adult female beagles varies from $16 \%$ per year to over $300 \%$ per year (Kimmel and Jee, 1982). Remodelling of the total bone mass per year for humans is given as $5-15 \%$, with estimates of the whole body trabecular bone turnover rate ranging from $10-15 \%$ per year to $40-55 \%$ (Fernandez-Tresguerres-Hernandez-Gil et al., 2006; Kimmel and Jee, 1982).

With regard to cortical bone, variation in bone turnover at different sites is also demonstrated, with rib cortical bone in young adult beagles having an annual turnover rate of approximately $18 \%$ while midshaft cortical bone of long bones is less than 1\% (Polig and Jee, 1989). In addition to these differences in bone turnover, age does not only affect normal bone turnover (Jee et al., 1970) but may also affect the bone response in relation to implant materials. Magee et al. (1989) demonstrate that there is significantly higher bone-implant interface strength in young greyhounds compared with older greyhounds. It is concluded that this is due to an age related decrease in bone remodelling ability (Magee et al., 1989).

\section{Sheep}

\section{Usage}

While the use of dogs for orthopaedic research still outnumbers sheep, over the last decade sheep numbers are increasing. In the period of 1990-2001, sheep were used in $9-12 \%$ of orthopaedic research involving fractures, osteoporosis, bone-lengthening and osteoarthritis, in comparison with just over $5 \%$ in the period from 1980 1989 (Martini et al., 2001). This increase in usage may be related to the ethical issues and negative public perception of using companion animals for medical research.

\section{Macrostructure}

Most of the literature reports that the dog is more suitable as a model for human bone from a biological standpoint than the sheep; however, adult sheep offer the advantage of being of a more similar body weight to humans and having long bones of dimensions suitable for the implantation of human implants and prostheses (Newman et al., 1995), which is not possible in smaller species such as rabbits or smaller breeds of dog.

\section{Microstructure}

While macroscopically, sheep bones may represent human bones relatively closely, histologically, the bone structure of the sheep is quite different (Fig. 1a-c). Sheep are described as having a predominantly primary bone structure (osteons less than $100 \mu \mathrm{m}$ diameter containing at least two central blood vessels and the absence of a cement line (deKleer, 2006)) in comparison with the largely secondary bone of humans (Eitel et al., 1981). Age related changes in bone structure are also described, whereby sheep up to 3-4 years of age have a plexiform bone structure comprising a combination of woven and lamellar bone within which vascular plexuses are sandwiched (Newman et al., 1995, Fig. 1a). Secondary, Haversian (osteonal) remodelling in sheep (Fig. 1d) becomes more prevalent with age (Liebschner, 2004) and has been seen at 7-9 years of age (Newman et al., 1995). The location of onset of haversian remodelling also seems to vary with bone type, with the caudal femur and diaphysis of the radius and humerus showing the earliest signs of this type of remodelling (Newman et al., 1995).

\section{Bone composition}

Differences in bone density exist between the human and sheep, whereby sheep bone shows a significantly higher density and subsequently greater strength. Nafei et al. (2000) reports the apparent density (mass/ volume, reflecting the degree of porosity of bone) of sheep trabecular bone taken from the proximal tibia of adult sheep as being $0.61 \mathrm{~g} / \mathrm{cm}^{3}$ with an apparent ash density of $0.41 \mathrm{~g} /$ $\mathrm{cm}^{3}$ (ash mass/volume, reflecting the degree of bone mineralisation) (Nafei et al., 2000). This is higher than 


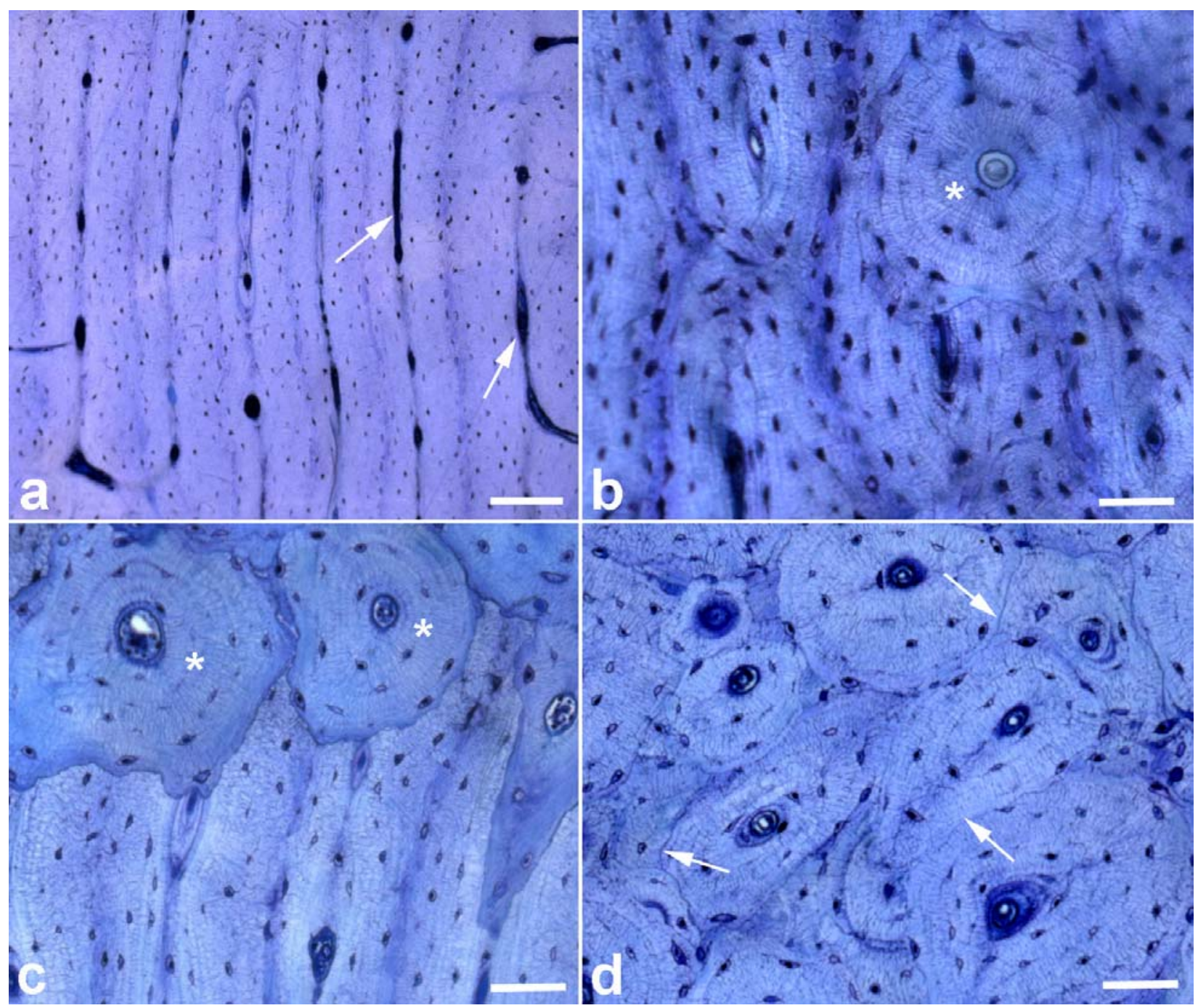

Figure 1. Ground and polished sections of MMA embedded sheep tibia stained with Toluidine blue. a) Plexiform or, as it is also called, laminar appearance of cortical bone with longitudinally arranged vessels (arrows) between the bone lamellae. Note the absence of a clearly visible cementline between adjacent lamellae. Scale bar $=200 \mu \mathrm{m}$. b) Remodelling of an area with originally plexiform bone which has been replaced by secondary osteons(*). Scale bar $=50 \mu \mathrm{m}$. c) Remodelling of plexiform bone in the immediate neigbourhood of an implant. During healing and subsequent remodelling new bone is deposited in form of secondary osteons, seen in the upper part of the image $(*)$. Scale bar $=50 \mu \mathrm{m}$. d) Transversely cut secondary bone with numerous osteons that can be clearly distinguished. Note the cementlines that separate neighbouring osteons (arrows). Scale bar $=50 \mu \mathrm{m}$.

reported values for human femoral trabecular bone which has an apparent density and an apparent ash density of $0.43 \mathrm{~g} / \mathrm{cm}^{3}$ and $0.26 \mathrm{~g} / \mathrm{cm}^{3}$ respectively, in other words the sheep femur has a trabecular bone density 1.5-2 times greater than that of humans (Liebschner, 2004). However, differences may change with location. For example, Liebschner (2004) reports that the apparent density of the trabecular bone from sheep vertebrae has an apparent density of $60+0.16 \mathrm{~g} / \mathrm{cm}^{3}$ - in contrast to the human vertebral body, in which the apparent density is $0.14+0.06 \mathrm{~g} / \mathrm{cm}^{3}$. This demonstrates that location must be considered when contemplating differences between human and sheep bones. It should be noted that unfortunately no age information is given in the above study and it remains unclear as to whether this could also influence the result. However it seems justified to assume that sheep have significantly greater trabecular bone density compared with humans.
In terms of mineral composition, Ravaglioli et al. (1996) performed an evaluation of bone from humans, cattle, sheep and dogs. The findings from this study conclude that, apart from the early stages of physiological growth in which there is partial substitution of $\mathrm{Mg}^{2+}$ for $\mathrm{Ca}^{2+}$ in tricalcium magnesium phosphate (TCMP), the mineral composition of humans and animals does not show significant differences (Ravaglioli et al., 1996).

\section{Bone remodelling}

While differences in bone structure are recognised, several studies argue that the sheep is still a valuable model for human bone turnover and remodelling activity (Chavassieux et al., 1987; den Boer et al., 1999; Pastoureau et al., 1989). In support of this theory, a study observing bone ingrowth into porous implants placed into the distal femur of sheep (a weight-bearing model), show that sheep and humans have a similar pattern of bone in-growth into 
porous implants over time. Although sheep are shown to have a larger amount of bone in-growth than humans, it is proposed that this is due to the greater amount of cancellous bone in the distal femur of sheep, in comparison with humans (Willie et al., 2004). Turner and Villanueva (1993) find that measurements of bone volume, osteoid volume and mineral apposition rate of 9-10 year old ewes are comparable with those of men and post-menopausal women in their 6-7th decade of life, suggesting that aged sheep may make suitable models for human osteopenic and osteoporotic bone.

As found in humans and dogs (Aerssens et al., 1997; Kimmel and Jee, 1982), it is likely that bone location may also alter bone composition and turnover in the sheep.

\section{Other \\ Age has been found to play a significant role in determining the amount of bone remodelling. The mechanical and physical properties of ovine bone and interestingly, bone from skeletally immature sheep showed a similar apparent density and apparent ash density to humans $\left(0.43 \mathrm{~g} / \mathrm{cm}^{3}\right.$ and $0.28 \mathrm{~g} / \mathrm{cm}^{3}$ respectively) (Nafei et al., 2000). Trabecular bone of skeletally immature sheep is weaker, less stiff, more deformable before failure, has higher shock absorptive qualities, contains more collagen and is less dense and more porous than that of skeletally mature sheep (Nafei et al., 2000). Thus it is essential to maintain a consistent age of sheep within a study and to be aware that age differences may make comparisons between studies difficult.}

\section{Goats}

\section{Usage}

While goats are the chosen species for $8.2 \%$ of animal studies published in the Journal of Orthopaedic Research (John Wiley \& Sons, Hoboken, NJ) between 1992 and 1996, their predominant use is in studies of cartilage, meniscal and ligamentous repair (An and Friedman, 1999). Like sheep, goats are considered food producing animals and thus also have the advantage of less critical public perception when used for research, than companion animals such as dogs. In comparison with sheep, goats tend to have a more inquisitive and interactive nature which may make confinement for long durations more challenging than for sheep. In certain regions such as south-east Asia where there is often a high temperature and humidity, goats are reported to be more tolerant to ambient conditions than other species such as sheep (Leung et al., 2001).

\section{Macrostructure}

Like sheep, goats also have a body size suitable for the implantation of multiple implants per goat or of larger, human implants and prostheses (Anderson et al., 1999; van der Donk et al., 2001).

\section{Microstructure}

Histologically, Qin et al. (1999) demonstrate that the tibial cortical bone of goats does not have homogeneously distributed Haversian systems (concentrically oriented lamellar bone containing a centrally located blood vessel, also known as osteons). Similar to the sheep, where the Haversian systems are non-uniformly distributed throughout individual bones, in the goat the Haversian systems are located primarily in the cranial, cranio-lateral and medial sectors of the tibial diaphysis, while the caudal sector is mainly comprised of lamellar bone (where the collagen fibres are arranged in sheets and do not contain a central blood vessel) (Qin et al., 1999).

\section{Bone composition}

In a paper by Liebschner (2004) discussing the biomechanical considerations of animal models used in bone tissue engineering, it is shown that while there are small differences in the apparent and ash density between the goat and humans, these differences are probably not as significant as the differences found between anatomic sites of the same species. As mentioned previously, the mineral composition of bone does not vary significantly across species and therefore one could conclude that this also holds true for the goat.

\section{Bone remodelling}

The literature reports that the goat is a suitable animal model for testing human implants and materials as they are considered to have a metabolic rate and bone remodelling rate similar to that of humans (Anderson et al., 1999; Spaargaren, 1994). Dai et al. (2005) also supported the use of goats for studies related to bone healing due to their comparable bone healing capacity and tibial blood supply with that of humans.

In a study of the incorporation of morsellised bone grafts under controlled loading conditions in goats and humans, Lamerigts et al. (2000) found that the goat is a suitable model to study bone graft incorporation, as the sequence of events occurring during incorporation of bone grafts is similar in humans and goats. However, the rate at which a bone graft is revascularised and converted into a vital trabecular structure is found to be faster in the goat, occurring at approximately 3 months in comparison to 8 months in humans.

There is little information comparing the utility of goats versus sheep for implant-related studies. Therefore the choice of which small ruminant to use most likely depends on availability and other factors.

\section{Pigs}

\section{Usage}

Pigs are reported as the subject of choice in a variety of studies including studies of osteonecrosis of the femoral head, fractures of cartilage and bone, bone ingrowth studies and studies evaluating new dental implant designs (An and Friedman, 1999; Buser et al., 1991; Sun et al., 1999). Commercial breeds of pig are generally considered undesirable for orthopaedic research due to their large growth rates and excessive final body weight. However, the development of miniature and micropigs has overcome this problem to some extent. Nevertheless, pigs are often 
considered difficult to handle, noisy and aggressive and are therefore overlooked in favour of more amenable species such as the sheep and goat (Newman et al., 1995; Swindle et al., 1988).

\section{Macrostructure}

With regard to bone anatomy, morphology, healing and remodelling, the pig is considered to be closely representative of human bone and therefore a suitable species of choice (Thorwarth et al., 2005). Similarities have been found in the femoral cross-sectional diameter and area between humans and pigs (Raab et al., 1991). However, pigs have a denser trabecular network (Mosekilde et al., 1993).

\section{Microstructure}

While having a denser trabecular network, the pig is described as having a lamellar bone structure which is similar to that of humans (Mosekilde et al., 1987).

\section{Bone composition}

When comparing the bone composition of various species, Aerssens et al. find that while canine bone most closely resembles human bone, porcine bone also shows similarities in bone mineral density and bone mineral concentration to human bone (Aerssens et al., 1998).

\section{Bone remodelling}

The literature describes the pig as having bone remodelling processes similar to humans, comprising both trabecular and intra-cortical BMU based remodelling (Mosekilde et al., 1987; Mosekilde et al., 1993). Laiblin and Jaeschke (1979) compare the bone regeneration rate of dogs, pigs and humans and find that pigs have a more similar rate of bone regeneration to humans than do dogs (dog, 1.5$2.0 \mathrm{~mm} /$ day; pig, $1.2-1.5 \mathrm{~mm}$ per day; human, $1.0-1.5 \mathrm{~mm}$ per day). In addition, in a study of the effects of fluoride on cortical bone remodelling in growing pigs the results show that control animals have a similar cortical bone mineralization rate to humans (Kragstrup et al., 1989).

\section{Rabbits}

\section{Usage}

The rabbit is one of the most commonly used animals for medical research, being used in approximately $35 \%$ of musculoskeletal research studies (Neyt et al., 1998). This is in part due to ease of handling and size. The rabbit is also convenient in that it reaches skeletal maturity shortly after sexual maturity at around 6 months of age (Gilsanz et al., 1988).

A drawback with the rabbit as an animal model for the assessment of multiple implant materials is its size limitation. The international standard for the biological evaluation of medical devices recommends a maximum of 6 implants (3 test and 3 control implants) per rabbit (International Standard ISO 10993-6, 1994). This is half the maximum number of implants recommended for sheep, dogs, goats and pigs. Also, the size of the implant which may be inserted is limited. Cylindrical implants are not recommended to be larger than $2 \mathrm{~mm}$ in diameter and $6 \mathrm{~mm}$ in length, again this is half that recommended for the other larger species mentioned (International Standard ISO 10993-6, 1994). Despite this, the rabbit remains a very popular choice of species for the testing of implant materials in bone.

\section{Macrostructure}

Clearly there are gross differences in the bone anatomy between the rabbit and human both in the size and shape of the bones and also in loading due to the differences in stance between the two species.

\section{Microstructure}

Histologically, rabbit long bones have a very different microstructure from humans (Wang et al., 1998). In comparison to the secondary bone structure of mature human bone, rabbits have a primary vascular longitudinal tissue structure, comprising vascular canals of osteons running parallel with the long axis of the bone, surrounding the medullary canal as well as the periosteal surface. The bone between these layers is comprised of dense haversian bone (Martiniakova et al., 2005). The maximum mean osteon diameter described by Martiniakova et al. (2005) was $223.79+47.69 \mu \mathrm{m}$ with a mean minimum diameter of $50.79+9.71 \mu \mathrm{m}$.

\section{Bone composition}

While there is minimal literature on the differences between human and rabbit bone composition and density, some similarities are reported in the bone mineral density (BMD) and subsequently the fracture toughness of mid-diaphyseal bone between rabbits and humans (Wang et al., 1998).

\section{Bone remodelling}

In comparison to other species, such as primates and some rodents, the rabbit has faster skeletal change and bone turnover (significant intracortical, Haversian remodelling) (Castaneda et al., 2006; Newman et al., 1995) (Gilsanz et al., 1988). This may make it difficult to extrapolate results from studies performed in rabbits onto the likely human clinical response. However, rabbits are commonly used for screening implant materials prior to testing in a larger animal model.

\section{Conclusion}

It is clear that each of the species discussed here demonstrate unique advantages and disadvantages in terms of their appropriateness as a model for demonstrating the response of bone tissue to an implant material. While nonhuman primates are often considered as the most appropriate model for human bone (Wang et al., 1998; Turner, 2001), there are clear ethical implications in using this species for medical research as well as cost, zoonotic disease risks and handling difficulties.

Of the species mentioned in this discussion, the dog is described as perhaps having the most similar bone structure to humans; however, there are ethical implications of using 
Table 1. Summary of four key attributes in terms of similarity between animal and human bone.

$\begin{array}{lllll} & \text { Canine } & \text { Sheep/Goat } & \text { Pig } & \text { Rabbit } \\ \text { Macrostructure } & ++ & +++ & ++ & + \\ \text { Microstructure } & ++ & + & ++ & + \\ \text { Bone Composition } & +++ & ++ & +++ & ++ \\ \text { Bone Remodelling } & ++ & ++ & +++ & +\end{array}$

+ least similar, ++ moderately similar, +++ most similar.

companion animals for medical research. While species such as the sheep and pig are not as ethically emotive, they may pose housing, handling and availability issues which may not be as critical with rabbits, even though rabbits may be the least similar in bone structure and properties to the human.

While no species fulfils the requirements of an ideal animal model, an understanding of the differences in bone macroscopic, microscopic and remodelling attributes is likely to improve the choice of animal species and interpretation of results from these in vivo studies.

\section{References}

Aerssens J, Boonen S, Joly J, Dequeker J (1997) Variations in trabecular bone composition with anatomical site and age: potential implications for bone quality assessment. J Endocrinol 155: 411-421.

Aerssens J, Boonen S, Lowet G, Dequeker J (1998) Interspecies differences in bone composition, density, and quality: potential implications for in vivo bone research. Endocrinology 139: 663-670.

An YH, Friedman RJ (1999). Animal selections in orthopaedic research. In: Animal Models in Orthopaedic Research (An YH, Friedman RJ, eds) CRC Press LLC, Boca Raton, FL, pp 39-57

Anderson ML, Dhert WJ, de Bruijn JD, Dalmeijer RA, Leenders H, van Blitterswijk CA, Verbout AJ (1999) Critical size defect in the goat's os ilium. A model to evaluate bone grafts and substitutes. Clin Orthop Relat Res 364: 231-239.

Bloebaum RD, Merrell M, Gustke K, Simmons M (1991) Retrieval analysis of a hydroxyapatite-coated hip prosthesis. Clin Orthop Relat Res 267: 97-102.

Bloebaum RD, Ota DT, Skedros JG, Mantas JP (1993) Comparison of human and canine external femoral morphologies in the context of total hip replacement. J Biomed Mater Res 27: 1149-1159.

Buser D, Schenk RK, Steinemann S, Fiorellini JP, Fox $\mathrm{CH}$, Stich H (1991) Influence of surface characteristics on bone integration of titanium implants. A histomorphometric study in miniature pigs. J Biomed Mater Res 25: 889-902.

Carlsson L, Rostlund T, Albrektsson B, Albrektsson T (1988) Implant fixation improved by close fit. Cylindrical implant-bone interface studied in rabbits. Acta Orthop Scand 59: 272-275.

Castaneda S, Largo R, Calvo E, Rodriguez-Salvanes F, Marcos ME, Diaz-Curiel M, Herrero-Beaumont G
(2006) Bone mineral measurements of subchondral and trabecular bone in healthy and osteoporotic rabbits. Skeletal Radiol 35: 34-41.

Chavassieux P, Pastoureau P, Boivin G, Charhon S, Chapuy M, Delmas P, Meunier P (1987) Effects of sodium fluoride on bone remodeling in ewes. J Bone Miner Res 2 Suppl 1: abstract 359.

Dai KR, Xu XL, Tang TT, Zhu ZA, Yu CF, Lou JR, Zhang XL (2005) Repairing of goat tibial bone defects with BMP-2 gene-modified tissue-engineered bone. Calcif Tissue Int 77: 55-61.

Davies CM, Jones DB, Stoddart MJ, Koller K, Smith E, Archer CW, Richards RG (2006) Mechanically loaded ex vivo bone culture system 'Zetos': systems and culture preparation. Eur Cell Mater 11: 57-75.

deKleer, V (2006). Development of bone. In: Bone in Clinical Orthopaedics, (Sumner-Smith G, ed) W.B. Saunders Co, Philadelphia, PA, pp 1-80

den Boer FC, Patka P, Bakker FC, Wippermann BW, van Lingen A, Vink GQ, Boshuizen K, Haarman HJ (1999) New segmental long bone defect model in sheep: quantitative analysis of healing with dual energy x-ray absorptiometry. J Orthop Res 17: 654-660.

Egermann M, Goldhahn J, Schneider E (2005) Animal models for fracture treatment in osteoporosis. Osteoporos Int 16 Suppl 2: S129-S138.

Eitel F, Klapp F, Jacobson W, Schweiberer L (1981) Bone regeneration in animals and in man. A contribution to understanding the relative value of animal experiments to human pathophysiology. Arch Orthop Trauma Surg 99: 59-64.

Fernandez-Tresguerres-Hernandez-Gil I, AloberaGracia MA, del Canto Pingarron M, Jerez LB (2006) Physiological bases of bone regeneration I. Histology and physiology of bone tissue. Med Oral Patol Oral Cir Bucal 11: E47-E51.

Gilsanz V, Roe TF, Gibbens DT, Schulz EE, Carlson ME, Gonzalez O, Boechat MI (1988) Effect of sex steroids on peak bone density of growing rabbits. Am J Physiol 255: E416-E421.

Gong JK, Arnold JS, Cohn SH (1964). Composition of trabecular and cortical bone. Anat Rec 149: 325-332.

Hanks CT, Wataha JC, Sun Z (1996) In vitro models of biocompatibility: a review. Dent Mater 12: 186-193.

Hazzard DG, Bronson RT, McClearn GE, Strong R (1992) Selection of an appropriate animal model to study aging processes with special emphasis on the use of rat strains. J Gerontol 47: B63-B64.

Huffer WE, Benedict JJ, Turner AS, Briest A, Rettenmaier R (2006) Repair of sheep long bone cortical defects with Colloss ${ }^{\circledR}$, Colloss $E \AA$, Ossaplast $\AA$, Ortho and 
iliac crest autograft. Proc 52nd Orthop Res Soc, Chicago II (Abstr.):890.

International Standard ISO 10993-6 (1994) Biological evaluation of medical devices - Part 6. 1-11.

Jee, WS, Bartley, MJ, Cooper, R, Dockum, N (1970). The beagle as an experimental dog. Ames:Iowa State University Press Pages 162-188.

Kimmel DB, Jee WS (1982) A quantitative histologic study of bone turnover in young adult beagles. Anat Rec 203: 31-45.

Kirkpatrick CJ, Krump-Konvalinkova V, Unger RE, Bittinger F, Otto M, Peters K (2002) Tissue response and biomaterial integration: the efficacy of in vitro methods. Biomol Eng 19: 211-217.

Kragstrup J, Richards A, Fejerskov O (1989) Effects of fluoride on cortical bone remodeling in the growing domestic pig. Bone 10: 421-424.

Kuhn JL, Goldstein SA, Ciarelli MJ, Matthews LS (1989) The limitations of canine trabecular bone as a model for human: a biomechanical study. J Biomech 22: 95-107.

Laiblin C, Jaeschke G (1979) Klinisch-chemische Untersuchungen des Knochen- und Muskelstoffwechsels unter Belastung bein Göttinger Miniaturschwein - eine experimentelle Studie (Clinical-chemical investigations of the metabolism of bone and muscle under stress in the Göttiningen miniature pig - an experimental study), Berl Münch Tierärztl Wschr 92: 124

Lamerigts NM, Buma P, Huiskes R, Schreurs W, Gardeniers J, SlooffTJ (2000) Incorporation of morsellized bone graft under controlled loading conditions. A new animal model in the goat. Biomaterials 21: 741-747.

Leung KS, Siu WS, Cheung NM, Lui PY, Chow DH, James A, Qin L (2001) Goats as an osteopenic animal model. J Bone Miner Res 16: 2348-2355.

Liebschner MA (2004) Biomechanical considerations of animal models used in tissue engineering of bone. Biomaterials 25: 1697-1714.

Magee FP, Longo JA, Hedley AK (1989) The effect of age on the interface strength between porous coated implants and bone. Trans Orthopaed Res Soc 14: 575

Martini L, Fini M, Giavaresi G, Giardino R (2001) Sheep model in orthopedic research: a literature review. Comp Med 51: 292-299.

Martiniakova M, Omelka R, Chrenek P, Ryban L, Parkanyi V, Grosskopf B, Vondrakova M, Bauerova M (2005) Changes of femoral bone tissue microstructure in transgenic rabbits. Folia Biol (Praha) 51: 140-144.

Mosekilde L, Kragstrup J, Richards A (1987) Compressive strength, ash weight, and volume of vertebral trabecular bone in experimental fluorosis in pigs. Calcif Tissue Int 40: 318-322.

Mosekilde L, Weisbrode SE, Safron JA, Stills HF, Jankowsky ML, Ebert DC, Danielsen CC, Sogaard CH, Franks AF, Stevens ML, Paddock CL, Boyce RW (1993) Calcium-restricted ovariectomized Sinclair S-1 minipigs: an animal model of osteopenia and trabecular plate perforation. Bone 14: 379-382.

Nafei A, Danielsen CC, Linde F, Hvid I (2000) Properties of growing trabecular ovine bone. Part I: Mechanical and physical properties. J Bone Joint Surg Br 82: 910-920.
Nahid M, Bottenberg P (2003) L'intérêt des cultures cellulaires dans la recherche de matériaux dentaires biocompatibles. (Importance of cell cultures in biocompatible dental materials research). Rev Belge Med Dent 58: 189-196.

Newman E, Turner AS, Wark JD (1995) The potential of sheep for the study of osteopenia: current status and comparison with other animal models. Bone 16: 277S$284 \mathrm{~S}$.

Neyt JG, Buckwalter JA, Carroll NC (1998) Use of animal models in musculoskeletal research. Iowa Orthop J 18: 118-123.

Pastoureau P, Arlot M, Caulin F, Barlet J, Meunier P, Delmas P (1989) Effects of oophorectomy on biochemical and histological indices of bone turnover in ewes. J Bone Miner Res 4: S237, abstract 477.

Pizzoferrato A, Ciapetti G, Stea S, Cenni E, Arciola CR, Granchi D, Savarino L (1994) Cell culture methods for testing biocompatibility. Clin Mater 15: 173-190.

Polig E, Jee WS (1989) Bone structural parameters, dosimetry, and relative radiation risk in the beagle skeleton. Radiat Res 120: 83-101.

Qin L, Mak AT, Cheng CW, Hung LK, Chan KM (1999) Histomorphological study on pattern of fluid movement in cortical bone in goats. Anat Rec 255: 380387.

Raab DM, Crenshaw TD, Kimmel DB, Smith EL (1991) A histomorphometric study of cortical bone activity during increased weight-bearing exercise. J Bone Miner Res 6: 741-749.

Ravaglioli A, Krajewski A, Celotti GC, Piancastelli A, Bacchini B, Montanari L, Zama G, Piombi L (1996) Mineral evolution of bone. Biomaterials 17: 617-622.

Richards RG, Stiffanic M, Owen GR, Riehle M, ap Gwynn I, Curtis AS (2001) Immunogold labelling of fibroblast focal adhesion sites visualised in fixed material using scanning electron microscopy, and living, using internal reflection microscopy. Cell Biol Int 25: 1237-1249.

Schimandle JH, Boden SD (1994) Spine update. The use of animal models to study spinal fusion. Spine 19: 1998-2006.

Schmidt C, Ignatius AA, Claes LE (2001) Proliferation and differentiation parameters of human osteoblasts on titanium and steel surfaces. J Biomed Mater Res 54: 209215.

Spaargaren DH (1994) Metabolic rate and body size: a new view on the 'surface law' for basic metabolic rate. Acta Biotheor 42: 263-269.

Sun C, Huang G, Christensen FB, Dalstra M, Overgaard S, Bunger C (1999) Mechanical and histological analysis of bone-pedicle screw interface in vivo: titanium versus stainless steel. Chin Med J (Engl ) 112: 456-460.

Swindle MM, Smith AC, Hepburn BJ (1988) Swine as models in experimental surgery. J Invest Surg 1: 65-79.

Thorwarth M, Schultze-Mosgau S, Kessler P, Wiltfang J, Schlegel KA (2005) Bone regeneration in osseous defects using a resorbable nanoparticular hydroxyapatite. J Oral Maxillofac Surg 63: 1626-1633.

Turner AS (2001) Animal models of osteoporosis Necessity and limitations. Eur Cells Mater. 1: 66-81. 
Turner AS, Villanueva AR (1993) Static and dynamic histomorphometric data in 9- to 11-year old ewes. Poster Session Abstracts - ACVS: 413.

Urban RM, Jacobs JJ, Tomlinson MJ, Gavrilovic J, Black J, Peoc'h M (2000) Dissemination of wear particles to the liver, spleen, and abdominal lymph nodes of patients with hip or knee replacement. J Bone Joint Surg Am 82: 457-476.

van der Donk S, Buma P, Aspenberg P, Schreurs BW (2001) Similarity of bone ingrowth in rats and goats: a bone chamber study. Comp Med 51: 336-340.

Vico L, Chappard D, Alexandre C, Palle S, Minaire P, Riffat G, Morukov B, Rakhmanov S (1987) Effects of a 120 day period of bed-rest on bone mass and bone cell activities in man: attempts at countermeasure. Bone Miner 2: 383-394.

Wang X, Mabrey JD, Agrawal CM (1998) An interspecies comparison of bone fracture properties. Biomed Mater Eng 8: 1-9.

Wataha JC, Hanks CT, Sun Z (1994) Effect of cell line on in vitro metal ion cytotoxicity. Dent Mater 10: 156161 .

Willie BM, Bloebaum RD, Bireley WR, Bachus KN, Hofmann AA (2004) Determining relevance of a weightbearing ovine model for bone ingrowth assessment. J Biomed Mater Res A 69: 567-576.

\section{Discussion with Reviewers}

K. Johnson: Could you add a table giving the range of dimensions of one bone (say the femur) of each species for direct comparison, together with growth plate closure times.

Authors: Growth plate closure times are published elsewhere (Kilborn et al., 2002) (This review included the mouse, rat, rabbit, dog, cat, sheep, cow, horse and nonhuman primate.). In addition to this for some species such as the sheep, more specific growth plate closure times are published for individual bones (Martini et al., text reference). With regard to the bone dimensions for each species, these will vary significantly within each species depending on breed, for example Beagles compared to Border Collies and Rambouillet X sheep compared to Merino sheep. As a rough comparison of one bone between the dog and human, one may refer to the Synbone catalogue where the dimensions of the human femur are given as
$450 \mathrm{~mm}$ in length with a medullary canal size of $9-11 \mathrm{~mm}$, while the dog femur has a length of $215 \mathrm{~mm}$ and a medullary canal size of $8-10 \mathrm{~mm}$.

A. Ignatius: Many implant models for material testing are located in compact bone and not trabecular bone. Do you think that tissue-material interactions differ in both locations?

Authors: Yes, we expect that the tissue-material interactions would differ between cortical and cancellous bone especially with regard to the timeframe of remodelling. We have experienced this in our studies, where implants placed into the cortico-cancellous bone of the ribs and simultaneously in the tibial diaphyseal cortical bone demonstrated a different time-course of response to the same materials. One must also consider that bone location has a significant effect on bone turnover, and may influence the tissue-material interaction. Given these differences, it is important to choose an appropriate model based on the intended purpose of the implant material being studied

A. Ignatius: Do you think that bone healing mechanisms differ in bone with primary or secondary osteonal structure or in plexiform bone?

Authors: Bone healing mechanisms per se should not differ between the different types of bone tissue. Basically bone can heal by desmal (which leads to woven bone) and by endochondral ossification. However, especially in the case of implant testing one has to keep in mind that the vascular situation between the osteonal bone tissue and the plexiform bone is very different. It therefore has to be expected that the response of the tissue to a certain injury (which always involves the vascular system of the bone) is somewhat different. Plexiform bone not only is a characteristic feature of certain species but usually also of younger age. Therefore the remodelling / healing characteristics can be expected to be more rapid than in adult human (osteonal) bone.

\section{Additional Reference}

Kilborn SH, Trudel G, Uhthoff H. (2002) Review of growth plate closure compared with age at sexual maturity and lifespan of laboratory animals. Contemp Top Lab Anim Sci 41: 21-26. 